\title{
Facilitando o uso do Scratch por meio de atividade desplugada que introduz o estudo do plano cartesiano
}

\author{
Karine P. C. da Costa, Matheus S. Azevedo, Charles A. G. Madeira \\ Instituto Metrópole Digital - Universidade Federal do Rio Grande do Norte (UFRN) \\ Caixa Postal 1524 - 59.078-970 - Natal - RN - Brazil \\ karinepcdc@ufrn.edu.br, omatheusazevedo@gmail.com, charles@imd.ufrn.br
}

\begin{abstract}
There is a growing need for greater technological fluency. Several initiatives emerged to supply this demand. One of them originated Scratch, a visual programming environment for learning. In this paper we report an experience for teaching the Cartesian coordinate system through an unplugged computational activity in order to make easier to use Scratch with children from 9 to 11 years-old of Elementary School. This activity allowed us to do experiments using the character navigation system with the children who could easily transpose it into the Scratch environment, being able to increase the engagement in the tasks.
\end{abstract}

Resumo. Há uma necessidade cada vez maior da população em vir a ter proficiência tecnológica. Diversos movimentos internacionais e ferramentas têm surgido como resposta a essa demanda. Uma das ferramentas originárias é o Scratch, um ambiente de programação voltado para o ensino. Nesse artigo relatamos a experiência de introduzir o estudo do plano cartesiano por meio de uma atividade de computação desplugada a fim de facilitar o uso de Scratch com crianças de 9 a 11 anos do Ensino Fundamental. A atividade proposta permitiu experimentarmos o sistema de movimentação de personagens com as crianças que, em seguida, puderam transpor facilmente tal sistema para o ambiente de Scratch, gerando assim um maior engajamento nas tarefas.

\section{Introdução}

As novas formas de produção e distribuição do conhecimento estão provocando profundas mudanças na maneira de ensinar e aprender, criando um novo universo para o ecossistema da educação. Portanto, para acompanhar as mudanças e evoluções da sociedade, é necessário haver um enriquecimento das escolas que permita dar espaço ao uso das tecnologias digitais para proporcionar a inovação e a melhoria do processo de ensino-aprendizagem.

Uma direção que vem se popularizando nos últimos anos e tem incentivado o aparecimento de um grande número de iniciativas relacionadas ao uso das tecnologias digitais na educação é a do Pensamento Computacional [Wing 2006], que conta com o desenvolvimento de um corpo de pesquisas mundialmente robusto [Wing 2014; De Paula et al. 2014; Zanetti et al. 2016; Avila et al. 2016] e envolve a resolução de 
VII Congresso Brasileiro de Informática na Educação (CBIE 2018)

Anais dos Workshops do VII Congresso Brasileiro de Informática na Educação (WCBIE 2018)

problemas, projeção de sistemas e compreensão do comportamento humano, através da extração de conceitos fundamentais da ciência da computação.

Blikstein (2008) aponta que aprender a programar é uma das etapas fundamentais para o desenvolvimento das habilidades intrínsecas ao pensamento computacional. No entanto, mais do que aprender a programar, queremos que crianças, jovens e adultos programem para aprender coisas novas. A essência do "aprender a programar, programar para aprender" está no fato de que, para desenvolver o pensamento computacional, é exigido do indivíduo que ele lide com diversas etapas no processo de resolução de problemas tais como decomposição, reconhecimento de padrões, abstração e algoritmo, a fim de buscar soluções mais eficientes e, ao mesmo tempo, enriquecer a aprendizagem daquele conteúdo que está sendo trabalhado no projeto desenvolvido.

Scratch (https://scratch.mit.edu/) é uma ferramenta bastante utilizada no processo de aquisição das habilidades do pensamento computacional. No entanto, essa ferramenta impõe algumas dificuldades para crianças que ainda não dominam o conceito de plano cartesiano. $\mathrm{O}$ presente artigo visa contribuir neste sentido, por meio de um relato de experiência de computação desplugada realizado no Núcleo de Educação da Infância da Universidade Federal do Rio Grande do Norte (NEI-UFRN), para estimular nas crianças o aprendizado do plano cartesiano. Esta experiência consiste em uma tarefa de um projeto que tem como objetivo principal o uso do computador como instrumento de aumento do poder cognitivo e operacional das crianças. Os resultados obtidos a partir dos trabalhos realizados têm se mostrado bastante promissores pois as crianças passaram a compreender bem o plano cartesiano, permitindo desenvolvermos diversas outras tarefas com Scratch, fazendo uso correto do plano cartesiano como ferramenta para movimentação dos personagens nos cenários simulados.

\section{Referencial teórico e trabalhos relacionados}

O processo de aprendizado precisa ser uma experiência agradável sob o ponto de vista do aprendiz, de forma que, com motivação, a prática se torne mais eficaz. Uma abordagem que tem se mostrado instigante para as crianças no processo de desenvolvimento das estruturas básicas do pensamento computacional é aquela que une as metodologias da aprendizagem baseada em resolução de problemas [Boud e Feletti 1998; Savery 2006] e da aprendizagem baseada em jogos digitais [Prensky 2007; Felicia 2014] com técnicas de programação visual [Marji 2014].

A metodologia da aprendizagem baseada em resolução de problemas é uma estratégia formativa através da qual os aprendizes são confrontados a problemas contextualizados para os quais se empenham em encontrar soluções significativas, desenvolvendo assim o raciocínio lógico, o pensamento crítico e a criatividade. Quando associada a brincadeiras e atividades lúdicas, se insere como uma ótima forma de estímulo ao aprendizado e ao desenvolvimento de novas habilidades [Mattar 2010].

A metodologia da aprendizagem baseada em jogos digitais vem sendo considerada como uma estratégia diferenciada para o aprimoramento do processo ensino-aprendizagem pois acredita-se que se os jogos forem transportados para o ambiente educacional de forma planejada e criteriosa, poderão surgir boas maneiras de 
VII Congresso Brasileiro de Informática na Educação (CBIE 2018)

Anais dos Workshops do VII Congresso Brasileiro de Informática na Educação (WCBIE 2018)

ensino-aprendizagem e desenvolvimento de diversas habilidades e competências num contexto disciplinar e transdisciplinar [Chuang e Chen 2009; Whitton 2014].

Em relação ao ensino de programação, a metodologia da aprendizagem baseada em jogos desmistifica as dificuldades na medida em que a complexidade da programação passa a ser tratada de forma lúdica em formato de jogo digital. Aprender jogando é a mola mestra desta metodologia. A programação pode ser inserida neste contexto a partir de um paradigma visual, baseado em blocos, no qual ações são agrupadas para solucionar uma determinada tarefa.

Scratch permite associar todas essas metodologias, se mostrando atualmente como uma das ferramentas de programação visual mais utilizadas para estímulo ao pensamento computacional, conforme apontado em diversos trabalhos recentes de revisão sistemática que relataram os benefícios dos experimentos práticos na formação dos estudantes [Araujo et al. 2016; Souza e Castro 2016; Henrique e Tedesco 2017]. No entanto, diversos problemas ainda persistem, como por exemplo quando o Scratch é levado às salas de aula do Ensino Fundamental $\mathrm{I}$ e as crianças ainda não têm conhecimento básico sobre o plano cartesiano, tendo em vista que apenas noções introdutórias são discutidas no $5^{\circ}$ ano (BNCC). Por conta disso, observamos em aulas introdutórias de Scratch dificuldade em dominar a movimentação dos personagens na ferramenta, mesmo após uma apresentação gradual e simplificada do plano cartesiano. Portanto, foi desenvolvida uma aula desplugada para facilitar a apropriação do plano cartesiano no contexto do Scratch. Após essa aula foi verificado maior entendimento do uso do plano cartesiano e maior domínio da linguagem própria para locomoção neste.

\section{Metodologia do trabalho}

A experiência apresentada faz parte de um projeto empreendido no NEI-UFRN desde 2015, que é uma escola de Educação Infantil e Fundamental. Em sua fase piloto, esse projeto possibilitou a inserção de alguns conceitos de programação de computadores, por meio da resolução de problemas, utilizando jogos digitais disponíveis na plataforma da Hora do código (https://studio.code.org). No primeiro ano do projeto, apenas duas turmas do Ensino Fundamental foram contempladas, sendo uma do $2^{\circ}$ ano e outra do $3^{\circ}$ ano. Os avanços observados nesta primeira experiência estão disponíveis em [Marinheiro et al. 2016]. A partir do êxito obtido nessa etapa inicial, o projeto teve continuidade nos anos seguintes, abrangendo um número maior de crianças aproximadamente 150 - entre 6 e 10 anos de idade, primeiramente contando com 7 turmas do $1^{\circ}$ ao $4^{\circ}$ ano até chegar à situação atual que contempla 9 turmas do Ensino Fundamental da escola (do $1^{\circ}$ ao $5^{\circ}$ ano), totalizando aproximadamente 185 crianças. Até então o material utilizado com as crianças se concentrava nos cursos de 1 a 4 do catálogo Computer Science Fundamentals International disponível na Hora do código. No entanto, nesta última edição, houve uma modificação no projeto para, além dos cursos já explorados, introduzir também o uso de Scratch nas turmas do $4^{\circ}$ e $5^{\circ}$ anos.

No presente trabalho relatamos a nossa experiência de ensino com o Scratch no primeiro semestre de 2018. Usamos uma metodologia de desenvolvimento experimental e o planejamento teve o apoio de uma equipe multidisciplinar, contando com docentes com formação e atuação na área de Computação e de Educação, além de graduandos do Bacharelado de Tecnologia de Informação da UFRN. O objetivo principal desta 
VII Congresso Brasileiro de Informática na Educação (CBIE 2018)

Anais dos Workshops do VII Congresso Brasileiro de Informática na Educação (WCBIE 2018)

experiência é dar mais liberdade para as crianças desenvolverem projetos de programação, concretizando o que já foi estudado através da plataforma da Hora do Código nos anos anteriores, além de permitir a contextualização de conceitos estudados em outras disciplinas, como português, matemática e geografia, e tornar a aprendizagem mais lúdica.

Como etapa importante do projeto, contamos com uma ação de formação dos professores da escola para qualificá-los no tema do pensamento computacional. Isso proporcionou aprofundar a parceria com os professores no planejamento e execução das aulas, gerando um maior engajamento dos mesmos nas intervenções pedagógicas. $\mathrm{Na}$ primeira parte da formação buscou-se uma mobilização da importância do uso pedagógico das tecnologias e do pensamento computacional na atualidade. Em seguida, a formação continuou com a prática do uso das plataformas da Hora do Código e do Scratch.

Três turmas do NEI-UFRN participaram desse projeto, sendo uma turma de $4^{\circ}$ ano com 16 alunos (9 meninos e 7 meninas), que iniciaram o ano com 9 anos, e duas turmas de $5^{\circ}$ ano, uma matutina com 20 alunos ( 7 meninos e 13 meninas) e uma vespertina com 17 alunos (10 meninos e 7 meninas), iniciando o ano com 10 a 11 anos. No total são 53 alunos (26 meninos e 27 meninas). Por terem participado das edições anteriores do projeto, os alunos do $4^{\circ}$ matutino, do $5^{\circ}$ ano matutino e do $5^{\circ}$ ano vespertino já tinham, respectivamente, 2 anos, 2 anos e 3 anos de experiência prévia de programação.

As intervenções com os alunos eram semanais, duravam 45 minutos e contavam com os seguintes momentos:

- Roda inicial: acolhimento, encaminhamentos sobre as atividades propostas para a aula e retomada de conceitos aprendidos anteriormente;

- Apresentação de conceitos e instruções;

- Prática no Scratch com atendimento individual.

As quatro primeiras aulas se basearam nos planos de aula 21 e 22 propostos pelo site Programae (http://programae.github.io/blocos/planos/). O objetivo dessas aulas foi apresentar o Scratch e dar a base técnica necessária para que as crianças conseguissem fazer uma animação. No fim de cada aula foi solicitado fazer algum trabalho de animação no Scratch para sedimentar o que foi aprendido no dia.

\section{Dificuldades com o uso do Scratch}

Inicialmente, a analogia Cinema/Filme/Novela utilizada na área de trabalho do Scratch (ver Figura 1) foi apresentada, assim como a explicação do sistema de movimentação dos personagens (atores) no cenário (palco). O sistema de movimentação foi introduzido de maneira gradativa nas aulas, pois as crianças ainda não haviam aprendido o conceito de plano cartesiano.

Primeiramente, foi feito uma relação do sinal positivo com o movimento para a direita e para cima, assim como do sinal negativo com o movimento para a esquerda e para baixo. Em seguida, o plano cartesiano foi introduzido como um sistema de referência de pontos num plano, sendo solicitado para as crianças uma animação com tema livre em que pelo menos um personagem estivesse se movimentando. Então, em 
VII Congresso Brasileiro de Informática na Educação (CBIE 2018)

Anais dos Workshops do VII Congresso Brasileiro de Informática na Educação (WCBIE 2018)

outra aula, elas fizeram alterações em uma animação utilizando a ferramenta de remix (cópia de um projeto online do Scratch para o repositório pessoal), que consiste em uma menina andando na neve (ver Figura 2). A animação foi utilizada para revisar o conceito de evento (já trabalhado nos cursos da Hora do Código), introduzir o conceito de paralelismo (dois eventos ocorrendo ao mesmo tempo) e reforçar o que foi aprendido sobre movimentação de personagens. Para isso, foi solicitado que as crianças mudassem o movimento dos flocos de neve caindo na vertical para que caíssem na diagonal.

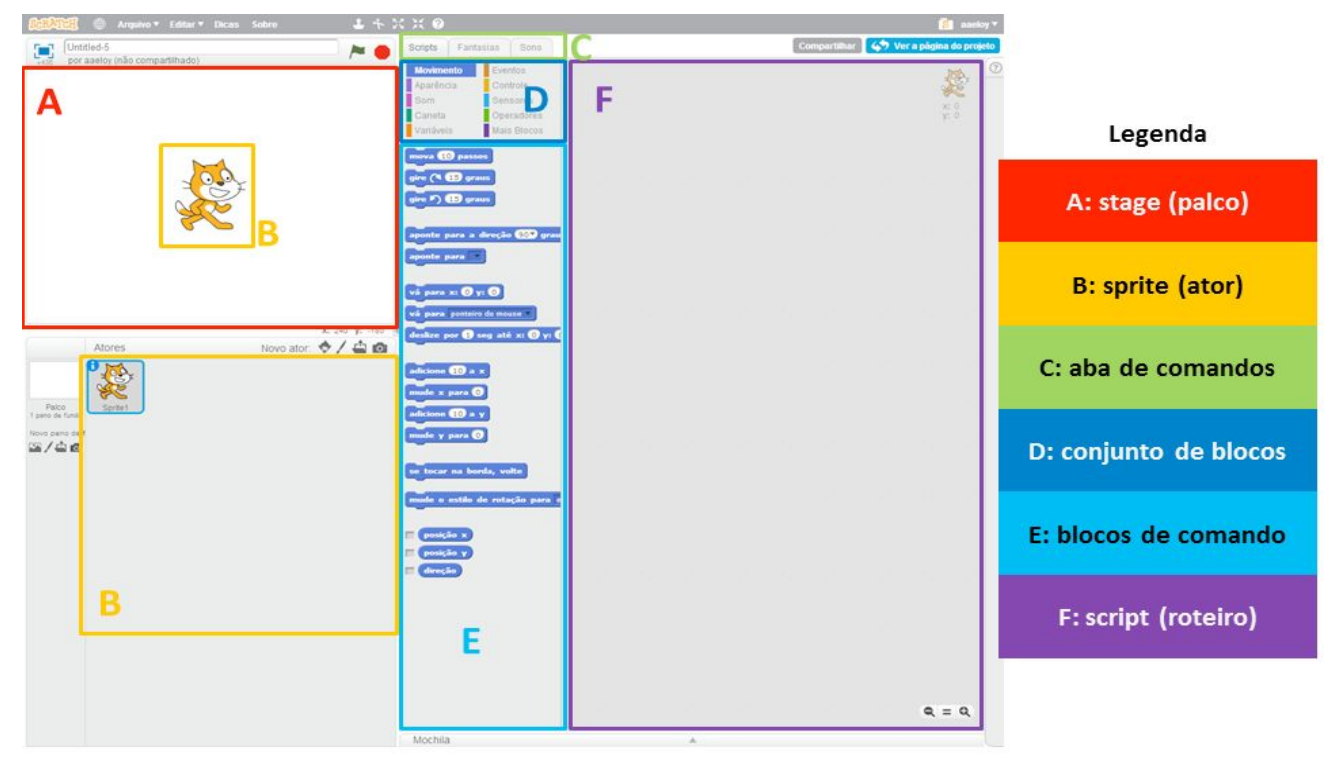

Figura 1. Analogia Cinema/Filme/Novela utilizada na área de trabalho do Scratch.

(Fonte: http://programae.github.io/blocos/aula21/)

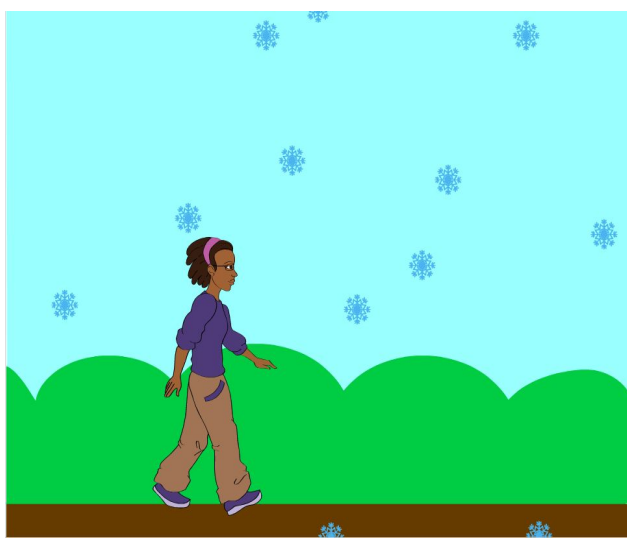

(a)

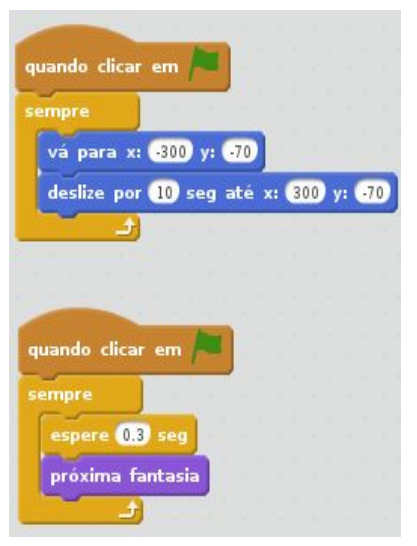

(b)

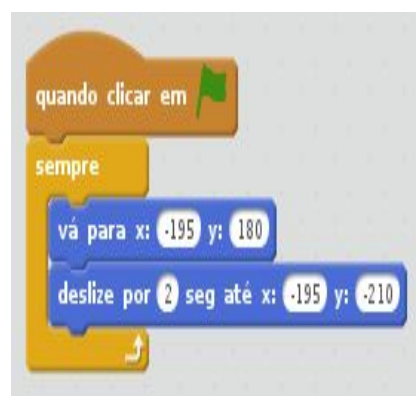

(c)

Figura 2. Animação desenvolvida no Scratch, exemplificando o conceito de evento e paralelismo na ferramenta: (a) uma menina caminhando na neve; (b) código que rege a movimentação da menina; (c) código que rege a movimentação dos flocos de neve.

No entanto, apesar de aparentemente entenderem os conceitos passados, a maioria das crianças não conseguia aplicá-los sem mediação nas animações, sendo, portanto, de grande valia a formação dos professores nesse momento. Ademais, pelo 
VII Congresso Brasileiro de Informática na Educação (CBIE 2018)

Anais dos Workshops do VII Congresso Brasileiro de Informática na Educação (WCBIE 2018)

plano cartesiano ser apenas utilizado durante as aulas do projeto, muito do que fora aprendido era esquecido de uma aula para outra, dificultando a progressão das aulas.

Visando diminuir esta dificuldade das crianças, uma intervenção de computação desplugada foi idealizada e realizada a fim de sedimentar a aprendizagem do plano cartesiano. Para isso, foi desenvolvido um jogo, chamado Jogo da Conquista, cuja temática foi inspirada no tema de pesquisa de uma das turmas participantes do projeto, referente aos continentes do planeta.

\section{Jogo da Conquista}

O Jogo da Conquista consiste em separar a turma em grupos, cada uma recebendo um mapa-múndi com um sistema de coordenadas cartesiano (ver Figura 3a) e um cartão de objetivos (ver Figura 3b) com três continentes que devem ser conquistados para obter a vitória. Para conquistar um continente é necessário que o grupo movimente a sua tropa pelo mapa até chegar em alguma coordenada situada dentro desse continente. Inicialmente cada grupo posiciona a sua tropa em uma coordenada dentro de um dos submarinos presentes do mapa. Na sua rodada, um grupo joga dois dados que determinarão a movimentação de suas tropas (os valores obtidos nos dados tem peso 10) e discute para que posição irá se movimentar no fim de sua rodada, em que o grupo precisará especificar qual seu movimento no eixo X e no eixo Y. Finalizada a rodada, a coordenada final da tropa é marcada no mapa projetado no quadro. Por exemplo, se em uma rodada são obtidos os valores 4 e 2 nos dados, os jogadores podem mover 20 (ou -20) no eixo $\mathrm{X}$ e 40 (ou -40) no eixo $\mathrm{Y}$ ou escolher mover 40 (ou -40) no eixo $\mathrm{X}$ e 20 (ou -20) no eixo Y. Vence o jogo quem conquistar todos os continentes que estão no seu cartão de objetivos.

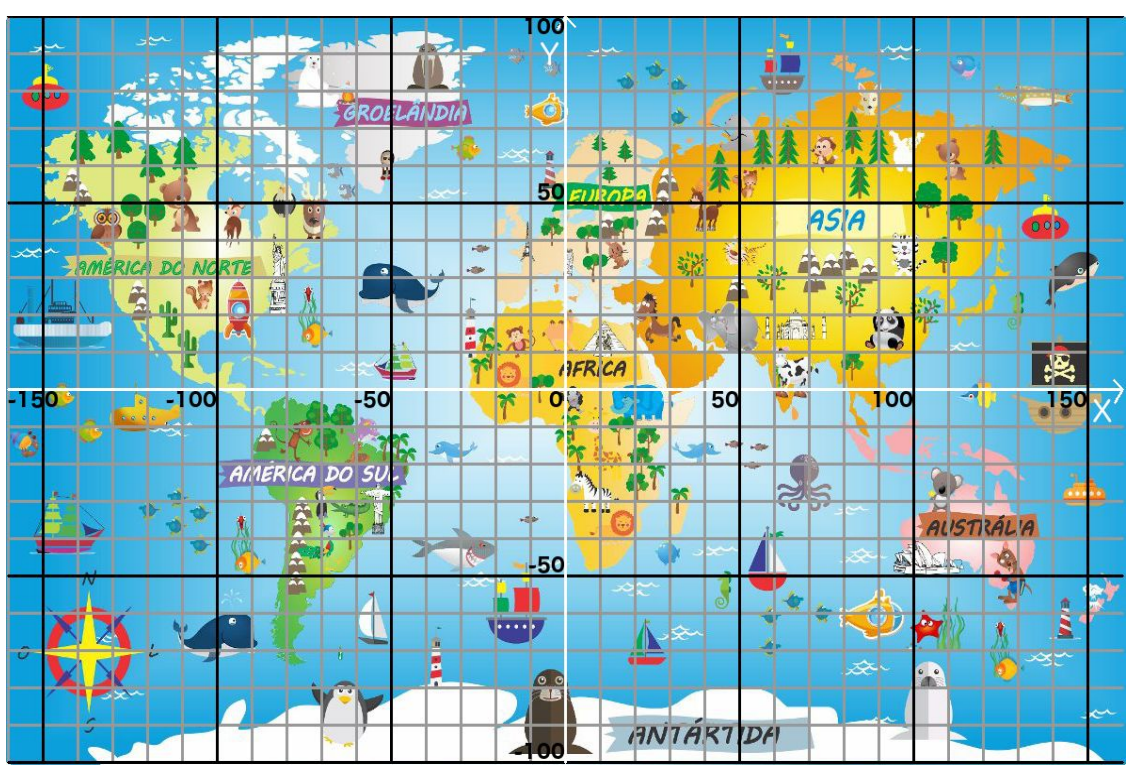

(a)

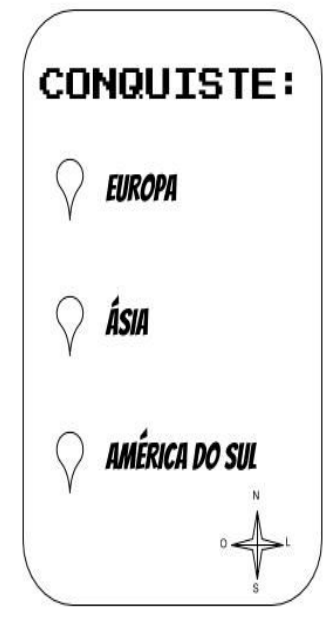

(b)

Figura 3. (a) Mapa-múndi discretizado utilizado no Jogo da Conquista; (b) cartão de objetivos. (Fonte: https://bit.ly/2xvZ2D4) 
VII Congresso Brasileiro de Informática na Educação (CBIE 2018)

Anais dos Workshops do VII Congresso Brasileiro de Informática na Educação (WCBIE 2018)

Com a aplicação do Jogo da Conquista nas turmas do NEI-UFRN, foi possível constatar que as crianças consideraram a tarefa envolvente, se esforçando para cumprir as regras estabelecidas, o que permitiu adquirirem o conhecimento básico necessário sobre o plano cartesiano. Conforme será discutido na seção de resultados obtidos, tivemos uma resposta positiva com o uso dessa abordagem, observando posteriormente um maior conforto dos alunos em realizar a movimentação dos personagens no ambiente de Scratch.

A utilização de uma linguagem adequada para a atividade de locomoção no plano cartesiano foi de fundamental importância para que os alunos se acostumassem com esse sistema de localização espacial e conseguissem realizar movimentação no mesmo. Ao final da aula, também foi importante fazer uma relação do cenário do Jogo da Conquista com o sistema de movimentação utilizado no ambiente de Scratch, de forma que a transposição do conceito fosse feita de maneira natural e contextualizada.

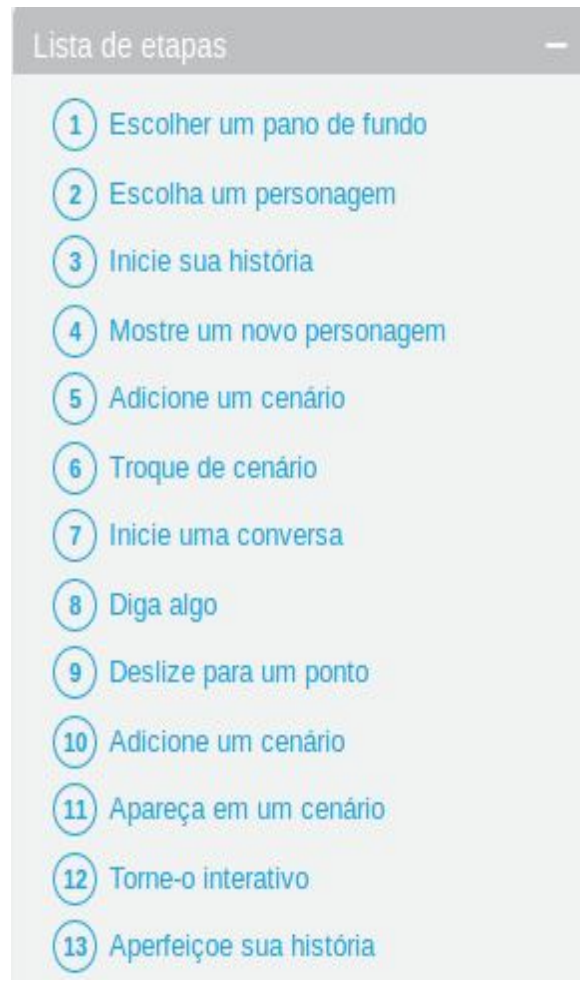

(a)

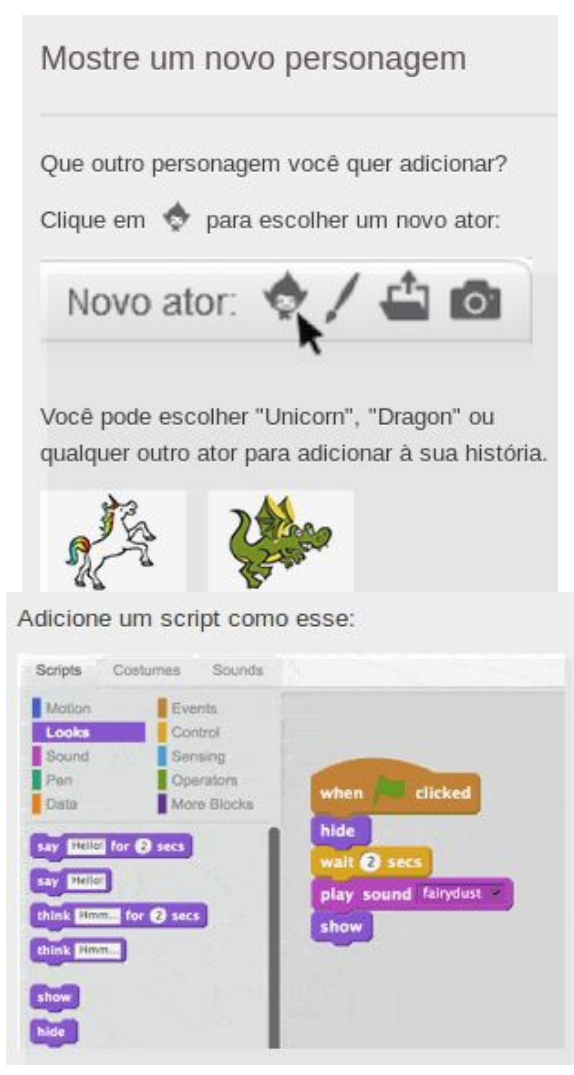

(b)

Figura 4. (a) Índice do tutorial "Criar uma história" do Scratch; (b) Recortes da seção "Mostre um novo personagem" do tutorial.

Com a evolução das aulas, o grau de complexidade da atividade de programação foi aumentando, sendo solicitado para que as crianças criassem uma história animada no ambiente de Scratch, utilizando as habilidades já adquiridas com o plano cartesiano. Desta vez, foi utilizado um tutorial disponível na plataforma online (http://www.scratch.mit.edu/), acessível a partir do menu "Dicas / Criar uma História" 
VII Congresso Brasileiro de Informática na Educação (CBIE 2018)

Anais dos Workshops do VII Congresso Brasileiro de Informática na Educação (WCBIE 2018)

(ver Figura 4), que levou as crianças a aprenderem os comandos básicos necessários para a criação de uma história. Parte do tutorial, na época, estava disponível somente em inglês, o que acabou sendo uma certa barreira para alguns alunos, necessitando assim a disponibilização da tradução das palavras. Apesar de algumas crianças não terem conseguido terminar o tutorial durante o período de duas aulas, avanços significativos foram conseguidos pois elas evoluíram satisfatoriamente na qualidade e na complexidade dos códigos produzidos.

\section{Resultados obtidos}

Os resultados reunidos nesta seção são frutos das observações coletivas e individuais em sala de aula e da análise dos projetos desenvolvidos pelos alunos.

Observamos que a roda inicial foi um instrumento importante, pois permite estruturar a aula e facilita a retomada de conceitos aprendidos, além de ser um espaço de diálogo com as crianças. Desta forma, as mediações na roda foram utilizadas para a concretização do aprendizado e sua transposição para outros contextos. Além disso, foi oferecida uma oportunidade para as crianças compartilharem dificuldades e frustrações, o que se mostrou importante para guiar o planejamento das aulas seguintes.

Também ficou claro que as mediações, nos momentos da roda e de um atendimento individual, foram fundamentais para oferecer apoio emocional e técnico aos alunos, além de guiá-los no processo criativo. Desta forma, o papel da formação dos professores neste projeto foi crucial para o engajamento dos docentes nesses momentos e no planejamento das aulas.

Entre as atividades desenvolvidas pelas crianças, solicitamos uma animação de tema livre, que contivesse pelo menos um personagem se movimentando pelo palco. Duas aulas foram necessárias para a elaboração dessa animação. Esta atividade teve como objetivo a introdução e ambientalização das crianças na nova ferramenta. A turma que apresentou maior dificuldade de cumprir as atividades propostas foi a do $4^{\circ}$ ano, o que nos levou a criar a dinâmica do Jogo da Conquista para sedimentar o aprendizado do plano cartesiano.

Antes da introdução do Jogo da Conquista, a atividade foi concluída por cerca de $20 \%$ das crianças do $4^{\circ}$ ano, enquanto que nos $5^{\circ}$ anos, matutino e vespertino, a taxa de sucesso foi de cerca de $75 \%$ e $65 \%$, respectivamente. Após a dinâmica do Jogo da Conquista, foi notório o maior domínio (prático e conceitual) dos comandos de movimentação no Scratch em todas as turmas, embora seja difícil quantificar essa melhora. O jogo não só ajudou na fixação dos referenciais positivo/negativo de localização, como contribuiu para que os alunos se familiarizassem com a noção de coordenadas. Ademais, as professoras das turmas relataram que as crianças também conseguiram aplicar esse conhecimento nas aulas de cartografia.

Por fim, é interessante comparar as duas plataformas de ensino. Diferentemente da Hora do Código, ambiente que as crianças já estavam familiarizadas, o Scratch não oferece objetivos concretos e uma visão mais clara da progressão. Notamos que deixar as crianças livres sem um domínio tão grande da ferramenta foi, em alguns momentos, frustrante por não conseguirem atingir os objetivos em uma aula. O tempo de aula curto (45 minutos) também é um dificultador para trabalhar com criatividade e programação 
VII Congresso Brasileiro de Informática na Educação (CBIE 2018)

Anais dos Workshops do VII Congresso Brasileiro de Informática na Educação (WCBIE 2018)

por conta da interrupção no processo criativo das crianças. Esse desânimo foi parcialmente sanado com o tutorial "Criar uma História" para guiar os alunos na criação de uma nova animação, também de tema livre, que foi aplicado durante duas aulas.

Percebemos que o tutorial serviu para dar um direcionamento e também um senso de progressão, já que a atividade envolve diversas etapas. Além disso, cumprem o papel de apresentar os comandos essenciais para a realização de uma história.

\section{Considerações finais}

O ensino de movimentação de personagens no Scratch é mais desafiador quando não se tem um conhecimento prévio do sistema de coordenadas cartesianas. Para contornar esse problema, uma atividade de computação desplugada, chamada Jogo da Conquista, foi idealizada e utilizada com três turmas do Ensino Fundamental I, com crianças do $4^{\circ}$ e $5^{\circ}$ anos. A atividade se mostrou bastante interessante por ser de fácil aplicação, contando com regras simples e envolventes, ao mesmo tempo em que permitiu maior fixação e familiaridade do uso do plano cartesiano como ferramenta de localização de pontos no espaço.

Apesar de apresentar um modelo instrucionista, os tutoriais online disponíveis no Scratch se mostram como recursos bastante interessantes para ambientação na ferramenta e ensino de comandos básicos, além de dar um senso de progressão. Portanto, eles são adequados como lições introdutórias.

O nosso próximo passo será trabalhar com a adaptação de textos redigidos pelas crianças para transformá-los em histórias animadas no ambiente de Scratch. A ideia da proposta é trabalhar em colaboração com os professores nas aulas de português. Para auxiliar nesse processo, utilizaremos um documento similar ao modelo simplificado para design de jogos (SGDD) proposto por Motta (2013) a fim de facilitar o processo de execução das tarefas. Esse será o primeiro grande projeto das turmas. A ideia de animar uma história de autoria própria foi recebida com bastante motivação pelas crianças. Em seguida, trabalharemos no sentido de elaborar jogos relacionados aos temas de pesquisa de cada turma.

Por fim, por Scratch ser um ambiente de desenvolvimento aberto, uma mediação qualificada é fundamental para o que todas as potencialidades dessa ferramenta sejam utilizadas. A mediação é importante não só para dar um direcionamento e apoio psicológico para as crianças, mas principalmente para guiar o aprendizado inicial da ferramenta e fornecer auxílio técnico quando necessidades específicas de programação surgem à medida que os projetos aumentam em nível de complexidade. Nesse sentido, torna-se clara a necessidade de investimento em cursos de formação para os professores.

\section{Referências}

Araujo, A., Andrade, W., Guerrero, D. (2016). Um Mapeamento Sistemático sobre a Avaliação do Pensamento Computacional no Brasil. Anais dos Workshops do V Congresso Brasileiro de Informática na Educação (CBIE 2016), p.1147-1158.

Avila, C., Bordini, A., Marques, M., Cavalheiro, S. e Foss, L. (2016). Desdobramentos do Pensamento Computacional no Brasil. Anais do Simpósio Brasileiro de Informática na Educação (SBIE-2016), p.200-209. 
VII Congresso Brasileiro de Informática na Educação (CBIE 2018)

Anais dos Workshops do VII Congresso Brasileiro de Informática na Educação (WCBIE 2018)

Blikstein, P. (2008). O Pensamento Computacional e a Reinvenção do Computador na Educação. Disponível em: <http://bit.ly/11XlbNn>.

Boud, D., Feletti, G. (1998). The Challenge of Problem-Based Learning, Kongan Page.

Chuang, T.-Y., Chen, W.-F. (2009). Effect of Computer-Based Video Games on Children: An Experimental Study. Educational Technology \& Society, 12(2):1-10.

De Paula, B., Valente, J. e Burn, A. (2014). O uso de jogos digitais para o desenvolvimento do currículo para a Educação Computacional na Inglaterra. Currículo sem Fronteiras, 14(3):46-71.

Felicia, P. (2014). Game-based Learning: Challenges and Opportunities. Cambridge Scholars Publishing.

Henrique, M. Tedesco, P. (2017). Uma Revisão Sistemática da Literatura sobre Conhecimentos, Habilidades, Atitudes e Competências Desejáveis para Auxiliar a Aprendizagem de Programação. Anais dos Workshops do VI Congresso Brasileiro de Informática na Educação (CBIE 2017), p.1162-1171.

Marinheiro, F., Cordeiro, S., Madeira, C. , Silva, I., Souza, D., Costa, P., e Fernandes, G. (2016). Ensinando crianças do ensino fundamental a programar computadores com o auxílio de jogos digitais. Revista Tecnologias na Educação, v. 12, p. 1-18.

Marji, M. (2014). Learn to Program with Scratch: A Visual Introduction to Programming with Games, Art, Science, and Math. No Starch Press.

Mattar, J. (2010). Games em educação: como os nativos digitais aprendem. Pearson Prentice Hall.

Motta, R., Junior, J. (2013). Short game design document (SGDD). Anais do XII Simpósio Brasileiro de Jogos e Entretenimento Digital (SBGames 2013), p. 115-121.

Prensky, M. (2007). Digital Game-Based Learning. McGraw-Hill.

Savery, J. (2006). Overview of Problem-Based Learning: Definitions and Distinctions. In The Interdisciplinary Journal of Problem-Based Learning, 1(2).

Souza, S., Castro, T. (2016). Investigação em Programação com Scratch para Crianças: uma Revisão Sistemática da Literatura. Anais dos Workshops do V Congresso Brasileiro de Informática na Educação (CBIE 2016), p.1078-1086.

Whitton, N. (2014). Digital Games and Learning: Research and Theory. Routledge.

Wing, J. (2006). Computational Thinking. Communications of the ACM, 49(3):33-36.

Wing, J. (2014). Computational Thinking Benefits Society. 40th Anniversary Blog of Social Issues in Computing. Disponível em: <http://bit.ly/2d9PrKn>.

Zanetti, H., Borges, M. e Ricarte, I. (2016). Pensamento Computacional no Ensino de Programação: Uma Revisão Sistemática da Literatura Brasileira. Anais do Simpósio Brasileiro de Informática na Educação (SBIE-2016), p.21-30. 